\section{Evaluation of the weight loss of raw beef cuts vacuum- packaged with two different techniques}

\author{
Simone Stella, ${ }^{1}$ Daniela Garavaglia, ${ }^{2}$ \\ Giorgia Francini, ${ }^{2}$ Valeria Viganò, ${ }^{2}$ \\ Cristian Bernardi, ${ }^{1}$ Erica Tirloni ${ }^{1}$
}

${ }^{1}$ Department of Health, Animal Science and Food Safety, University of Milan;

${ }^{2}$ Sealed Air Corporation Italy, Rho, Italy

\section{Abstract}

In the present study, 25 cuts of shank form adult cattle coming from the same slaughtering batch, were withdrawn just after manual sectioning/deboning, and each divided into two pieces (Prox and Dist) of approximately the same weight, that were vacuum packaged by using two different packaging systems: vacuum chamber machine with a bag material and a thermoforming packaging machine with top and bottom webs named BAG and THF respectively. The packed cuts were stored at $2-3^{\circ} \mathrm{C}$ for 20 days. The drip loss was calculated at the end of the storage as the difference between drained weight and net. Internal muscle $\mathrm{pH}$ and $\mathrm{pH}$ of the exudate present in the package and microbiological analyses (by pooling the samples) were performed at T0 and at the end of the storage. The drip loss, was significantly lower with BAG packaging: this difference was evident after 20 days of storage (average \pm STD BAG $v s$ $\mathrm{THF}=1.04 \pm 0.36 \%$ vs $1.71 \pm 0.42 \%$; $\mathrm{P}<0.01$ ). The values were, in general, low for both the packaging systems, never above $2 \%$. Moreover, shrink bag packages are characterized by better overall pack appearance and less plastic weight per pack. Forming step reduce the thickness of thermoforming material lowering the mechanical resistance and the barrier to oxygen, on the contrary after shrinking bag materials are thickened. The $\mathrm{pH}$ of muscles was stable, although a slight increase was evidenced after 20 (average \pm STD BAG vs $\mathrm{THF}=5.73 \pm 0.05$ vs 5.78 $\pm 0.09 ; \mathrm{P}<0.01$ ), due to the ageing of meat. The $\mathrm{pH}$ of the exudate was equal at T20 (average \pm STD $\mathrm{BAG} v s \mathrm{THF}=5.34 \pm 0.20$ vs $5.33 \pm 0.17$ ). The drip loss didn't influence the development of all the microflora; in particular $\mathrm{LAB}$, that represented the main microbial population, showed a gradual increase from T0 (2.20 $\pm 0.41 \mathrm{Log} C F U / g)$ to T20 (average $\pm \mathrm{STD} \mathrm{BAG} v s \mathrm{THF}=4.76 \pm 0.29 \mathrm{Log}$ $\mathrm{CFU} / \mathrm{g}$ vs $4.75 \pm 0.0 .15 \mathrm{Log} \mathrm{CFU} / \mathrm{g})$.
Enterobacteriaceae showed an increase, if compared to the initial counts, due to the prolonged storage and the gradual growth of ephemeral microorganisms, without differences among the two series (Enterobacteriaceae: $\mathrm{T} 0=<1.7 \mathrm{Log} \mathrm{CFU} / \mathrm{g}$ to $\mathrm{T} 20$ average $\pm \mathrm{STD} \mathrm{BAG} v s \mathrm{THF}=$ $2.83 \pm 0.77 \mathrm{Log} C F U / g$ vs $3.09 \pm 0.0 .70 \mathrm{Log}$ $\mathrm{CFU} / \mathrm{g}$ ). In conclusion, the use of the BAG system demonstrated to have an effect in reducing the drip loss of beef cuts during the refrigerated storage, with only slight influence on the other characteristics of raw meat.

\section{Introduction}

The weight loss of beef cuts during the ageing and the storage is a natural event, due to the leakage of exudate. This loss has an economic impact on the market of fresh beef, due to the decreased yield and to the perception of the consumers, who negatively consider the view of an evident drip of fluid from meat (Aaslyng et al., 2010).

The water holding capacity of meat reaches its minimum value when muscle $\mathrm{pH}$ value is near the isoelectric point of the proteins (Lawrie, 1974). This phenomenon cannot be totally avoided by the producers, also if it can be limited. Drip loss is thought to result from lateral shrinkage of myofibrils, determining the expulsion of the water into the muscles extracellular space (Offer and Knight, 1988; Offer et al., 1989). After death and during rigor mortis, large spaces between the fiber bundles and the perimysial network and between fibers and the endomysial network, appear. These spaces can function as longitudinal channels for the fluids, that may reach the meat surface and be lost (Offer and Cousins, 1992).

Various factors affect the entity of drip loss of meats: species and age of the animals, muscle typology (red/white fibres, fat content), pre-slaughter stress (affecting meat ultimate $\mathrm{pH}$ ), rigor, temperature, method of suspension, electrical stimulation, cutting (influencing the membrane integrity), packaging and storage temperature (den Hertog-Meischke and Smulderst, 1998; Malton and James, 1983; Offer and Knight, 1988; O'Keeffe and Hood, 1981; Payne et al., 1997; Strydom and HopeJones, 2014).

Meats stored without packaging are generally subjected to surface evaporation: this can lead to a significant weight loss and to the need for trimming the dried surface of meats. Thus, packaging systems, and in particular vacuum packaging, are applied with the beneficial effect of avoiding the evaporation (Seideman and Durland, 1983).
Correspondence: Erica Tirloni, Department of Health, Animal Science and Food Safety, University of Milan, Via Celoria 10, 20133, Milan, Italy.

Tel.: +39.02-50317855 - Fax: +39.02-50317870. E-mail: erica.tirloni@unimi.it

Key words: drip loss, raw beef, packaging, $\mathrm{pH}$, microbiology.

Acknowledgements: The authors would thank Pellegrini Spa. for providing meat cuts.

Contributions: The authors contributed equally.

Conflict of interest: The authors declare no potential conflict of interest.

Funding: None.

Received for publication: 14 February 2019. Revision received: 8 July 2019.

Accepted for publication: 9 July 2019.

This work is licensed under a Creative Commons Attribution-NonCommercial 4.0 International License (CC BY-NC 4.0).

(C) Copyright: the Author(s), 2019

Licensee PAGEPress, Italy

Italian Journal of Food Safety 2019; 8:8111

doi:10.4081/ijfs.2019.8111

However, the use of vacuum packaging causes itself a certain degree of drip loss, due to the negative pressure and the physical squeezing applied during packaging, that continues during the prolonged storage (Aspè et al., 2008; Payne et al., 1998).

Some studies have also faced the effect of the application of packaging shrinkage on the drip loss of vacuum packaged meat, evidencing its positive effect presumably due to the avoidance of air sacks and air bubbles, thus, diminishing the space for drip to form in, or to softer packaging, or a combination of the two (Aspè et al., 2008, Beltran, 2007; Vazquez et al., 2004). From a technological point of view, vacuum bag packing is a method of packaging that removes air from the plastic bag prior to sealing using vacuum chamber machines. In vacuum packaging technique, the product is placed in a plastic bag within the machine on the seal bar, the lid is closed and applying negative pressure ambient air is removed with sealing of the packages. After sealing the bag, the chamber is refilled with air by the automatic opening of a vent to the outside. This oncoming pressure squeezes all remaining air in the bag. The lid is then opened and the product removed. Following the vacuum chamber machine, a hot water shrink tunnel ensure the pack shrinking.

A variant of vacuum packaging tech- 
nique is thermoforming vacuum packing: this can be done with thermoforming machine that forms the package from rolls of packaging web. Products are loaded into the thermoformed pockets, the top web is laid and sealed under vacuum, producing vacuum packaged products.

Considering the materials used, the plastic bag is a thin material with high shrink properties and improved optical and saleability properties, while thermoforming top and bottom webs are flexible nonshrinkable barrier forming webs.

The storage of raw meat in vacuum conditions has a significant impact also on the microbial population present on the surface of meat cuts. The absence of oxygen favours the development of anaerobic/facultative anaerobic bacteria; in optimal conditions, the microbial population is dominated by Lactic Acid Bacteria (LAB), that can exert a protective competitive action towards the main spoilage and pathogenic microorganisms (Borch et al., 1996; Erichsen and Molin, 1981; Nissen et al., 1996). LAB, thanks to the production of organic acids (mainly lactic acid), cause also an acidification of the surface of meat, thus influencing the drip loss.

The effect of drip loss on the microbial population of meat is not already cleared. It is likely that the presence of a higher amount of fluid within the pack could lead to a faster microbial growth, due to the higher availability of nutritive substrate (Vázquez et al., 2004; Lagerstedt et al., 2011). The results obtained comparing packaging systems with variable amount of space (vacuum vs skin pack), evidenced a slower growth in skin packaging, although this could be due to the lower presence of residual air within the package, and not directly to the presence of fluid (BarrosVelazquez et al., 2003). In particular, Barros-Velazquez et al. (2003) in beef maintained with vacuum skin packaging or traditional vacuum packaging, with differences of 2.07, 1.60, and 1.25 log CFU/g in loads of total aerobic mesophilic count, anaerobes and lactic acid bacteria, respectively.

Aim of the present study was the evaluation of two different vacuum packaging systems on the weight loss of raw beef cuts.

\section{Materials and Methods}

\section{Meat used for the trial}

Samples of shank form adult cattle (A category, uncastrated male animals aged from 12 months to less than 24 months) coming from the same slaughtering batch, were chosen. The animals were born, reared and slaughtered in Germany (two days before the test), and sectioned in an Italian deboning plant just before the test.

\section{Packaging materials used for the trial}

The meat cuts were packed with plastic shrinkable barrier bags, 45 micron thick using a vacuum chamber machine (BAG) and with formable barrier webs on thermoforming packaging machine: top web 54 micron and bottom web 275 micron thick (THF). A pre -trial was organized in order to well size the plastic bag and formed pocket to the selected meat cut and to define the best combination bottom/top web to ensure the right conditions for a comparison between the two packaging systems.

\section{Experimental plan}

The cuts were withdrawn just after manual sectioning/deboning, and each cut was divided into two pieces of approximately the same weight (Proximal-Prox and Distal-Dist). A total of 25 cuts were used. After deboning, meat surface samples were aseptically sampled by using a sterilized knife with the aim to perform microbial analyses of the initial microbial population. In order to take into account the difference between the proximal and distal part of the muscles (as the distal part has less "free" muscular surface and was thought to have a lower leakage), the proximal and the distal parts were equally distributed among the BAG and THF series. After packaging and sealing, the cuts were immediately refrigerated at $2-3^{\circ} \mathrm{C}$ for 20 days.

\section{Microbiological analyses}

For the microbiological analyses, samples were withdrawn by taking $4 \mathrm{~g}$ shares from the surface of each cut by sterile knife. Pooled samples were obtained every 4 samples, for a total of 5 samples for each sampling time and pack typology. Analyses were performed at $\mathrm{T} 0$ and at the end of the storage (T20). Total Bacterial Count was enumerated according to ISO 4833 method (Plate Count Agar, incubation at $30^{\circ} \mathrm{C}$ for 48/72 h). Count of Enterobacteriaceae was performed according to the ISO 21528 method (Violet Red Bile Glucose Agar, incubation at $37^{\circ} \mathrm{C}$ for $24 \mathrm{~h}$ ). Count of Lactic Acid Bacteria was performed according to the ISO 15214 method (MRS agar, incubation at $30^{\circ} \mathrm{C}$ for $48 \mathrm{~h}$ in anaerobiosis).

\section{pH measurement}

$\mathrm{pH}$ was measured by a pHmeter equipped with an infission probe. Two measurements were performed for each sample: internal muscle $\mathrm{pH}$ and $\mathrm{pH}$ of the liquid (exudate) present in the package. Analyses were performed at $\mathrm{T} 0$ and at the end of the trial (T20).

\section{Drip loss measurement}

The drip loss was calculated after 20 days by measuring the net weight calculated as: raw weight of the packaged cut - tare (weight of the dried package film) and by measuring drained weight of the cut (after gentle surface drying by paper); the difference between drained weight and net weight represented the drip loss, that was expressed as \% of net weight.

\section{Statistical analysis}

Results obtained were submitted to statistical analyses. Before the analysis, the results of the microbiological analyses were Log-transformed. The student-t test with paired data was used for the statistical analysis; levels of significance of $\mathrm{P}<0.05$ and $\mathrm{P}<0.01$ were considered.

\section{Results}

\section{Drip loss}

The results obtained after 20 days of storage of vacuum packaged beef are reported in Table 1. The loss of exudate into the pack is a natural event, due to the leakage of intramuscular fluids from the cut surface, and to the vacuum packaging. At day 20 , a significantly higher quantity of fluid was lost in THF series $(\mathrm{P}<0.01)$.

Considering the cut part as a single fac-

Table 1. Results of the drip loss measurement at $T_{20}$.

\begin{tabular}{|c|c|c|c|c|c|c|c|c|}
\hline Parameter & $\mathrm{D}_{20} \mathrm{BAG}$ & $\mathrm{D}_{20} \mathrm{THF}$ & $\mathrm{D}_{20}$ Prox & $\mathrm{D}_{20}$ Dist & $\mathrm{D}_{20}$ BAG-Prox & $\mathrm{D}_{20}$ BAG-Dist & $\mathrm{D}_{20}$ THF-Prox & $\mathrm{D}_{20}$ THF-Dist \\
\hline Mean Drip loss $(\%) \pm$ STD & $1.04 \%{ }^{\mathrm{B}} \pm 0.36$ & $1.71 \% \mathrm{~A} \pm 0.42$ & $1.40 \% \pm 0.60$ & $1.36 \% \pm 0.43$ & $0.98 \% \%^{\mathrm{B}} \pm 0.29$ & $1.12 \%^{\mathrm{B}} \pm 0.42$ & $1.89 \%{ }^{\mathrm{A}} \pm 0.48$ & $1.56 \%{ }^{\mathrm{A}} \pm 0.32$ \\
\hline
\end{tabular}


tor, no significant differences were detected between the proximal and the distal part of the cuts, also if a wider free muscular surface could suggest a higher loss in the proximal one.

The analysis of the combined effect of packaging technology and cut part confirmed the significantly higher fluid loss in THF series at day 20 , with a slightly higher value in THF proximal samples. Also, in this case, the prolonged storage resulted in the presence of very similar results among the series.

pH

The results of $\mathrm{pH}$ measurement performed in the muscle and in the exudate after a 20 days storage of vacuum packaged beef are reported in Table 2. The muscle $\mathrm{pH}$ detected in the samples at Day 0 was within the normal range for meat from adult cattle (5.7-5.8). No modifications were observed at Day 20 of storage. A significant difference between the packaging techniques was detected at T20 $(\mathrm{P}<0.01)$, with higher values in THF samples. Considering the cut part as a single factor, a higher $\mathrm{pH}$ value was detected in the distal part of the cuts, both at T20 $(\mathrm{P}<0.05)$. The analysis of the combined effect of packaging technology and cut part evidenced the higher value in THF distal samples at Day 20.

The $\mathrm{pH}$ of the fluid (Table 3 ) into the beef packs is usually lower than the muscle $\mathrm{pH}$, as it is influenced by the gradual growth of acidifying microflora (mainly lactic acidproducing $\mathrm{LAB}$ ), and tends to decrease during the meat storage. This typical trend was observed in both BAG and THS series, without a significant difference at T20.
Considering the cut part as a single factor, a higher $\mathrm{pH}$ value was detected in the proximal part of the cuts, at $\mathrm{T} 20(\mathrm{P}<0.01)$. The analysis of the combined effect of packaging technology and cut part didn't give a clear trend, as higher values were detected in BAG proximal and THF distal samples, without significant differences.

\section{Microbiological analyses}

The results obtained in microbiological analyses are summarized in Figure 1. Starting form values around $4 \mathrm{Log} \mathrm{CFU} / \mathrm{g}$ (that can be considered as normal for raw beef cuts), the Total Viable Count increased during the first part of the storage, reaching values near $7 \mathrm{Log} \mathrm{CFU} / \mathrm{g}$, that can be considered as normal for vacuum packaged beef stored for 20 days. Similar trends were observed for the two-sample series; significantly higher values were observed in BAG samples at T20 (Figure 1). Low initial LAB counts were detected in the samples, as expected; a gradual increase of these microorganisms was observed during the whole duration of the trials, as the refrigerated storage under vacuum favoured the selection and the growth of these psychrotrophic, anaerobic microorganisms. The same trend was observed for BAG and THF series, without evidencing any particular difference (Figure 1).

The low initial Enterobacteriaceae counts (Table 4) indicated the good hygiene condition of the cuts used for the trials; a gradual increase was observed for the whole trial duration, due to the selection of psychrotrophic, facultative anaerobic microorganisms. Slightly higher counts were detected in THF samples at T20, but the trend of the two series was very similar, without significant differences.

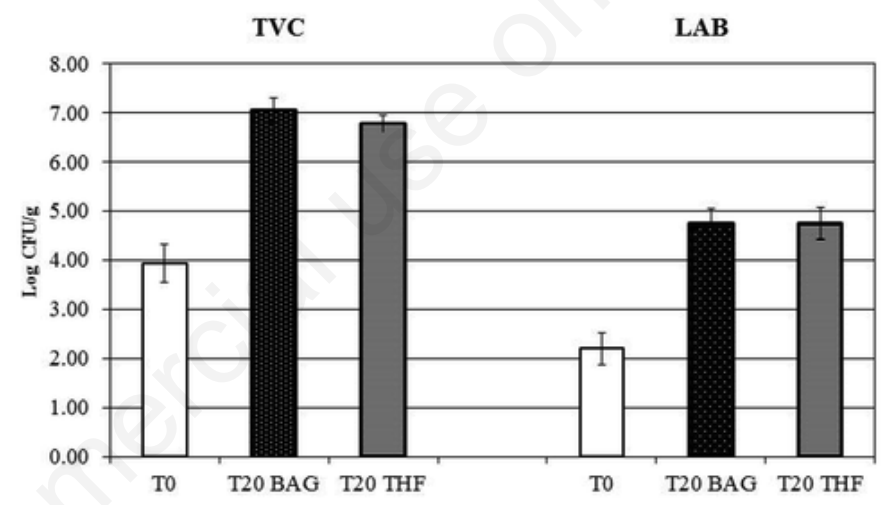

Figure 1. Boxplot graph of TVC and LAB values at T0 and T20. TVC: total viable count; LAB: lactic acid bacteria.

Table 2. Results of the $\mathrm{pH}$ measurement performed at $\mathbf{T}_{20}$.

\begin{tabular}{|c|c|c|c|c|c|c|c|c|c|}
\hline Parameter & $\mathrm{D}_{0}$ & $\mathrm{D}_{20} \mathrm{BAG}$ & $\mathrm{D}_{20}$ THF & $\mathrm{D}_{20}$ Prox & $\mathrm{D}_{20}$ Dist & $\mathrm{D}_{20}$ BAG-Prox & $\mathrm{D}_{20}$ BAG-Dist & $\mathrm{D}_{20}$ THF-Prox & $\mathrm{D}_{20}$ THF-Dist \\
\hline Mean muscle $\mathrm{pH} \pm \mathrm{SD}$ & $5.75 \pm 0.07$ & $5.73^{\mathrm{B}} \pm 0.05$ & $5.78^{\mathrm{A}} \pm 0.09$ & $5.74^{\mathrm{b}} \pm 0.05$ & $5.77^{\mathrm{a}} \pm 0.10$ & $5.74^{\mathrm{b}} \pm 0.06$ & $5.72^{\mathrm{b}} \pm 0.04$ & $5.74^{\mathrm{b}} \pm 0.04$ & $5.82^{\mathrm{a}} \pm 0.11$ \\
\hline
\end{tabular}

${ }_{\mathrm{A}, \mathrm{B}}$ Statistically significant difference $(\mathrm{P}<0.01)$; ${ }^{\mathrm{a}, \mathrm{b}}$ Statistically significant difference $(\mathrm{P}<0.05)$.

Table 3. Results of the $\mathrm{pH}$ exudate measurement performed at $\mathbf{T}_{20}$.

\begin{tabular}{|c|c|c|c|c|c|c|c|c|}
\hline Parameter & $\mathrm{D}_{20} \mathrm{BAG}$ & $\mathrm{D}_{20}$ THF & $\mathrm{D}_{20}$ Prox & $\mathrm{D}_{20}$ Dist & $\mathrm{D}_{20}$ BAG-Prox & $\mathrm{D}_{20}$ BAG-Dist & $\mathrm{D}_{20}$ THF-Prox & $\mathrm{D}_{20}$ THF-Dist \\
\hline Mean exudate $\mathrm{pH} \pm \mathrm{SD}$ & $5.34 \pm 0.20$ & $5.33 \pm 0.17$ & $5.37^{\mathrm{A}} \pm 0.19$ & $5.30^{\mathrm{B}} \pm 0.18$ & $5.45^{\mathrm{A}, \mathrm{a}} \pm 0.21$ & $5.23^{\mathrm{b}} \pm 0.10$ & $5.29^{\mathrm{B}} \pm 0.12$ & $5.36 \pm 0.21$ \\
\hline
\end{tabular}

A,BStatistically significant difference $(\mathrm{P}<0.01) ; \mathrm{a}, \mathrm{b}$ Statistically significant difference $(\mathrm{P}<0.05)$.

Table 4. Results of the counts of Enterobacteriaceae performed at T0 and $\mathrm{T}_{20}$.

\begin{tabular}{|c|c|c|c|}
\hline Sample & $\mathrm{D}_{0}(\log \mathrm{CFU} / \mathrm{g})$ & $\mathrm{D}_{20}$ BAG (Log CFU/g) & $\mathrm{D}_{20} \mathrm{THF}(\log \mathrm{CFU} / \mathrm{g})$ \\
\hline Pool n 1-5 & $<1.70$ & 2.00 & $<2.00$ \\
\hline Pool n ${ }^{\circ} 6-10$ & 2.18 & 3.45 & 3.43 \\
\hline Pool n 11-15 & 2.48 & 3.53 & 3.65 \\
\hline Pool n $16-20$ & 1.70 & 3.18 & 3.57 \\
\hline Pool n 21-25 & $<1.70$ & $<2.00$ & 2.78 \\
\hline Mean value $( \pm$ SD) & $1.95 \pm 0.36$ & $2.83 \pm 0.77$ & $3.09 \pm 0.70$ \\
\hline
\end{tabular}




\section{Discussion and Conclusions}

The effect of two packaging systems on weight loss of beef cuts stored for 20 days was compared; the loss of exudate by the meat, due to the action of vacuum and to the release of water from the muscle fibres, was significantly lower for vacuum shrink bag packaging. Moreover, shrink bag packages are characterized by better overall pack appearance and less plastic weight per pack. Forming step reduce the thickness of thermoforming material lowering the mechanical resistance and the barrier to oxygen, on the contrary after shrinking bag materials are thickened. The $\mathrm{pH}$ of muscles during the prolonged storage was substantially stable, with a slight increase among the series analysed after 20 days, due to the ageing of meat, due to the formation of nitrogen compounds; this was expected, as the gradual acidification is linked to the development of Lactic Acid Bacteria on the surface of meat, producing organic acids (mainly lactic acid). A sight but significant difference between the two packaging systems was detected after 20 days with lower values for BAG packaged samples. No constant differences were evidenced between the two half cuts (proximal and distal). The amount of exudate into the packages didn't influence the development of all the microorganisms enumerated in the samples (TVC, LAB, Enterobacteriaceae); thus, it was sufficient to allow a significant microbial growth. A significantly lower growth was reported in previous studies, but it was related to a different packaging system (vacuum skin packaging vs traditional vacuum packaging) (Barros-Velazquez et al., 2003; Taylor et al., 1990; Vazquez et al., 2004). A variability detected in some samples, should be considered as normal for meat primal cuts, and the initial microbiological population may be different depending on the slaughtering and deboning hygiene, that is not completely standardized. The statistical analysis was performed considering the coupled data, to take into account this variability. The use of the BAG system showed to have an effect in reducing the drip loss of beef cuts during the refrigerated storage, with slight influences on the other characteristics of raw meat. This is extremely important taking into account consumer influence purchasing decisions for meat appearance at the point of sale. The visibility of drip loss in meat packaging may have an impact on consumer preference (Aaslyng et al., 2010; Grobbel et al., 2008; Lagerstedt et al., 2011; Li et al., 2012) and in the end influence satisfaction when eating meat.

\section{References}

Aaslyng MD, Tørngren MA, Madsen NT, 2010. Scandinavian consumer preference for beef steaks packed with or without oxygen. Meat Sci 85:519-24.

Aspe E, Roeckel M, Marti MC, Jimenez R, 2008. Effect of pre-treatment with carbon monoxide and film properties on the quality of vacuum packaging of beef chops. Packaging Technol Sci 21:395404.

Barros-Velazquez J, Carreira L, Franco C, Vazquez BI, Fente C, Cepeda A, 2003. Microbiological and physicochemical properties of fresch retail cuts of beef packaged under an advanced vacuum skin system and stored at $4^{\circ} \mathrm{C}$. J Food Protect 66:2085-92.

Beltrán L, 2007. Sales Manager, Sealed Air Chile Industrial Ltda., Santiago de Chile, Chile. Personal communication.

Borch E, Kant-Muermans ML, Blixt Y, 1996. Bacterial spoilage of meat and cured meat products. Int $\mathrm{J}$ Food Microbiol 33:103-20.

Clausen I, Jakobsen M, Ertbjerg P, Madsen NT, 2009. Modified atmosphere packaging affects lipid oxidation, myofibrillar fragmentation index and eating quality of beef. Packaging Technol Sci 22:85-96.

den Hertog-Meischke MJA, Smulderst FJM, van Logtestijn JG, 1998. The effect of storage temperature on drip loss from fresh beef. J Sci Food Agricult 78;522-6.

Erichsen I, Molin G, 1981. Microbial flora of normal and high $\mathrm{pH}$ beef stored at $48 \mathrm{C}$ in different gas environments. J Food Protect 44:866-9.

Grobbel JP, Dikeman ME, Hunt MC, Milliken GA, 2008. Effects of different packaging atmospheres and injectionenhancement on beef tenderness, sensory attributes, desmin degradation, and display color. J Anim Sci 86:2697-710.

Kamenik J, Salakova A, Pavlik Z, Borilova G, Hulankova R, Steinhauserova I, 2014. Vacuum skin packaging and its effect on selected properties of beef and pork meat. Eur Food Res Technol 239:395-402.

Lagerstedt A, Ahnström ML, Lundström K, 2011. Vacuum skin pack of beef - A consumer friendly alternative. Meat Sci 88;391-6.

Lawrie RA, 1974. Meat Science. $2^{\text {nd }}$ edition. Pergamon Press, Oxford, UK.

Li X, Lindahl G, Zamaratskaia G, Lundström K, 2012. Influence of vacuum skin packaging on color stability of beef longissimus lumborum compared with vacuum and high-oxygen modified atmosphere packaging. Meat Sci 92;604-9.

Malton R, James SJ, 1983. Drip loss from wrapped meat on retail display. Meat Industry 56:3941.

Nissen H, Sorheim O. Dainty R, 1996. Effects of vacuum, modified atmospheres and storage temperature on the microbial flora of packaged beef. Food Microbiol 13:183-91.

Offer G, Knight P, 1988. The structural basis of water-holding in meat. In: Developments in Meat Science È4, ed Lawrie R A. Elsevier Applied Science, London, UK, pp 63-243.

Offer G, Knight P, Jeacocke R, Almond R, Cousins T, Elsey J, Parsons N, Sharp A, Starr R, Purslow P, 1989. The structural basis of water-holding, appearance and toughness of meat and meat products. Food Microstructure 8:151-70.

Offer G, Cousins T, 1992. The mechanism of drip production: formation of two compartments of extracellular space in muscle post mortem. J Sci Food Agricult 58:107-16.

O'Keeffe M, Hood DE, 1981. Anoxic storage of fresh beef. 2: colour stability and weight loss. Meat Sci 5:267-81.

Payne SR, Durham CJ, Scott SM, Devine C.E., (1998). The effects of non-vacuum packaging systems on drip loss from chilled beef. Meat Science 49, 277-287.

Payne SR, Durham CJ, Scott SM, Penney N, Bell RG, Devine CE, 1997. The effects of rigor temperature, electrical stimulation, storage duration and packaging systems on drip loss in beef. Proceedings of the 43rd International Congress of Meat Science and Technology, Auckland, (G1-22), pp. 592-593.

Seideman SC, Durland PR, 1983. Vacuum packaging of fresh beef: a review. J Food Quality 6:29-47.

Strydom PE, Hope-Jones M, 2014. Evaluation of three vacuum packaging methods for retail beef loin cuts. Meat Sci 98:689-94.

Taylor AA, Down NF, Shaw BG, 1990. A comparison of modified atmosphere and vacuum skin packing for the storage of red meats. Int J Food Sci Technol 25:98-109.

Vazquez BI, Carreira L, Franco C, Fente C, Cepeda A, Barros-Velazquez J, 2004. Shelf life extension of beef retail cuts subjected to an advanced vacuum skin packaging system. Eur Food Res Technol 218:118-22. 